\title{
An Analysis of Regenerative Braking and Energy Saving for Electric Vehicle with In-Wheel Motors
}

\author{
${ }^{1}$ Li-qiang Jin, ${ }^{2}$ Peng-fei Chen and ${ }^{3} *$ Yue Liu \\ State Key Laboratory of Automotive Simulation and Control, Jilin University, \\ Changchun, 130025 \\ 1jinlq@jlu.edu.cn, ${ }^{2}$ chen.pf6@gmail.com, ${ }^{3}$ liuyueresearch@163.com
}

\begin{abstract}
Based on the structural features of electric vehicle (EV) driven by in-wheel motors and the characteristics of low speed as well as high torque for in-wheel motors, regenerative braking method for in-wheel motors has been presented. All braking torque for vehicle deceleration is output by in-wheel motors under Medium-intensity braking condition for the sake of recovering the maximum braking energy. The vehicle dynamics model that includes the hydraulic braking system and in-wheel motors driving system has been built by AMESim software. Simulation has been carried out for vehicle driving conditions by NEDC cycle and FTP75 cycle. The result shows that the recovery rate of braking energy is increased dramatically by in-wheel motor braking method. The energy efficiency of electric vehicle has been improved more than 30\%. It is significant for electric vehicles to increase driving range and reduce costs.
\end{abstract}

Keywords : Electric vehicle, in-wheel motor, regenerative braking

\section{Introduction}

With ever increasing concerns on energy efficiency, energy diversification and environment protection, the development of the electric vehicle (EV) has taken on an accelerated pace [1]. Now, what is difficult is that the driving range of an EV is not cost effective. Based on energy recovery for the traditional automobile, regenerative braking for an EV has attracted considerable interest during the last 20-25 years. Regenerative braking is an efficient approach to extend the driving range of the EV without any additional cost; at the same time, it plays an important role in energy saving [2-5]. Recently, many efforts have been focused on developing models of the regenerative braking system and improving brake performance.

A detailed description of the regenerative braking algorithm was presented along with simulation results from a dynamic model of the parallel hybrid EV (HEV) [6]. A vehicle model, a slip ratio model and a vehicle speed observer were developed to control the antilock performance of an HEV during braking. Through an iterative learning process, the motor torque was optimized to keep the tire slip ratio corresponding to the peak traction coefficient during braking, and simulations were performed on a compact size vehicle [7]. A fuzzy controller algorithm was designed to accurately switch off the regenerative braking and at the same time to switch on the physical brakes [8]. In [9], the paper maximized the regenerative braking force, and the simulation results were presented. In [10], the paper calculated the fuel saving efficiency for a case with an ideal regenerative braking system. All these papers put forward the model of regenerative braking and analyzed the braking performance [6-10]. However, only the simulation results are presented, not the experimental results, which is not convincing. Furthermore, the method of improving energy recovery efficiency was validated 
by experiments [11]. The method of energy regenerative braking was analyzed for a brushless direct current (DC) motor, and the drive and control circuit were realized by digital signal processing (DSP) and EXB841 [12]. In [11, 12], the papers laid emphasis on digital implementation of the control method, and the classical PI control method was also applied. In [13], this paper presented the effect of rotating inertias on the power and energy for each component during regenerative braking of the vehicle. The results showed that the rotating inertias can contribute a significant fraction (8-13\%) of the energy recovery during deceleration because of the relatively lower losses of rotating components compared with vehicle inertia. It can be concluded that the energy recovery efficiency can be improved by a good control method. In this study, all braking events are categorized into four states and only one of them could be applied to braking events. The detailed states are described below from their paper.

\section{Feasibility Analysis and Design for In-Wheel Motor Braking System}

Generally, the regenerative braking system works together with the conventional friction brake for the following reasons: (a) the regenerative braking torque is not large enough to cover the required braking torque, (b) regenerative braking cannot be used for many reasons, such as the high state of charge (SOC) or high temperature of the battery to increase the battery life. In these cases, the conventional friction braking system works to supply the required braking force. Therefore, in order to apply regenerative braking, a control algorithm on how to distribute the braking force into the regenerative braking force and mechanical friction force is required with respect to the battery SOC, motor speed, etc. In addition, the regenerative braking control algorithm should take into the maximum use of the regenerative braking energy for further reduction of emissions and improvement of the fuel economy account.

\subsection{Feasibility Analysis}

During most of vehicle driving time, mild deceleration is used. In Figure 1, it has presented that decelerating at a rate steeper than $0.23 \mathrm{~g}$ happens in less than $1 \%$ approximately of all the braking cases [7], it is far less than the logic gate for anti-locking braking system working. Table 1 shows that the requirement of braking torque acting on front and rear axle at different deceleration for $1500 \mathrm{~kg}$ car where a and $\mathrm{g}$ denote the deceleration, FT denotes the front torque, RT denotes the rear torque. It can be concluded that the total brake torque is less than $600 \mathrm{~N} . \mathrm{m}$ to brake at $0.23 \mathrm{~g}$ deceleration and less than $200 \mathrm{~N}$.m for each wheel. The peak torque for in- wheel motor is enough to get this deceleration rate. Namely, the regenerative braking system only by in-wheel motor can satisfy the demand of brake torque for $99 \%$ deceleration condition of vehicle. The maximum braking deceleration can be $0.8 \mathrm{~g}$ during emergency braking condition. The brake torque requirement can be achieved to $2300 \mathrm{~N}$.m and $700 \mathrm{~N}$.m for each wheel based on consideration of braking force distribution. The peak torque of in-wheel motor is not enough to meet this requirement, especially at high speed. 


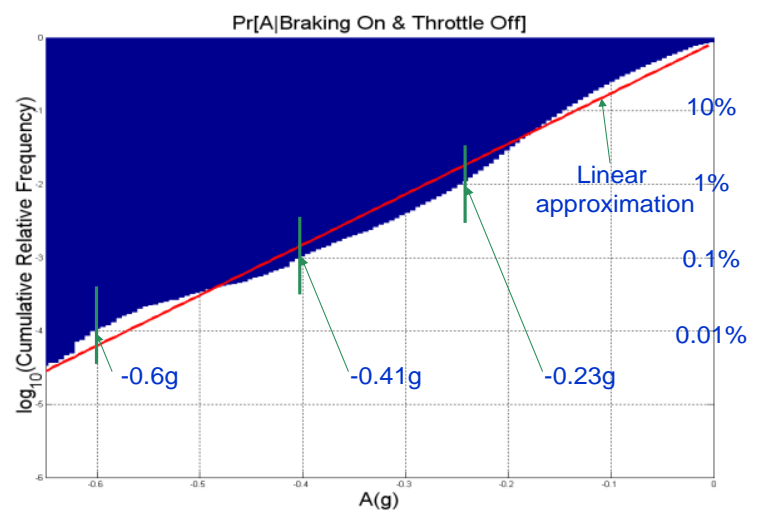

Figure 1. Automotive Brake Intensity Distribution

And so, the hydraulic braking system is essential for emergency braking condition. But the braking capacity of hydraulic braking system can be reduced for in wheel motor regenerative brake torque. The paper presents a novel composite regenerative braking system. It can be realized that the vehicle can be decelerated only by in wheel motor at low deceleration and by composite braking with hydraulic brake and in wheel motor at emergency braking condition.

Table 1. Different Torque Required for Braking Deceleration

\begin{tabular}{|c|c|c|c|}
\hline $\mathrm{g} /(\mathrm{g})$ & $\mathrm{a} /(\mathrm{m} \cdot \mathrm{s}-2)$ & $\mathrm{FT} /(\mathrm{Nm})$ & $\mathrm{RT} /(\mathrm{Nm})$ \\
\hline 0 & 0 & 0 & 0 \\
\hline 0.1 & 0.98 & 109 & 175 \\
\hline 0.2 & 1.96 & 228 & 339 \\
\hline 0.3 & 2.94 & 357 & 492 \\
\hline 0.4 & 3.92 & 496 & 635 \\
\hline 0.5 & 4.9 & 645 & 767 \\
\hline 0.6 & 5.88 & 804 & 889 \\
\hline 0.7 & 6.86 & 973 & 1000 \\
\hline 0.8 & 7.84 & 1152 & 1100 \\
\hline 0.9 & 8.82 & 1341 & 1190 \\
\hline 1 & 9.8 & 1540 & 1269 \\
\hline
\end{tabular}

\subsection{Design of the Regenerative Braking Program}

The basic idea is that a pressure buffer device is assigned in pressure transmission path between the braking pedal and master cylinder. There is no braking pressure produced in the wheel cylinder during small pedal travel substituted by in wheel motor brake torque. The wheel cylinder pressure increased quickly with pedal travel increasing to meet the 
requirement of emergency braking condition. Meanwhile, the pressure buffer device produces the spring force to simulate the feel when the driver stepping on the pedal. It transmits the vehicle braking pressure to driver by feedback.

The schematic of traditional brake system control mechanism is shown in Figure 2. The novel control mechanism presented in the paper is shown in Figure 3. A pre-pushed rod is assigned between the braking pedal and push rod. The pre-pushed rod is connected with braking pedal by connecting rod. The other end of pre-pushed rod is connected with push rod by sliding hinge. A distance between pre-pushed rod and push rod is set along the axial sliding direction. A pre-pressure spring is assigned between the pre-pushed rod and braking push rod. A pedal travel sensor is used to measure the pedal travel. A braking accumulator is connected with braking pipe to buffer the braking pressure.

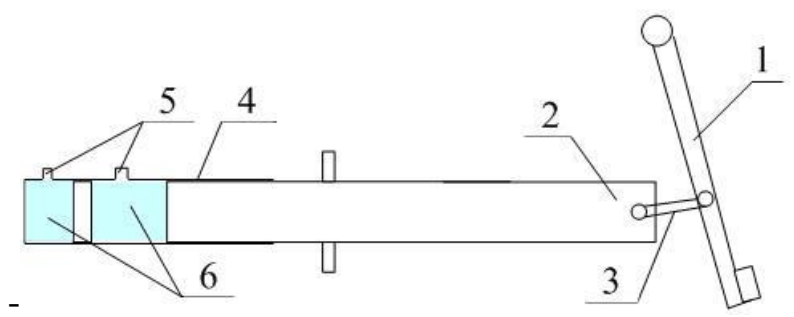

1) brake pedal 2) brake push rod 3) connecting rod 4) brake master cylinder 5) outlet of brake liquid 6) brake liquid

Figure 2. Conventional Hydraulic Brake Control Mechanism

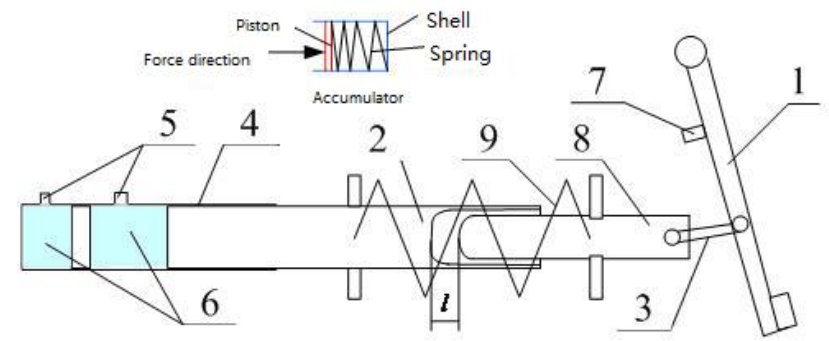

1) brake pedal 2) brake push rod 3) connecting rod

4) brake master cylinder 5) out let of brake liquid 6)brake liquid 7)pedal travel sensor 8)pre-pushed rod 9)pre-pressure spring

\section{Figure 3. In-wheel Motor Electromechanical Brake Actuation Mechanism}

\subsection{The Control Method of Mechanical and Electrical Composite Braking System}

The total brake torque requirement of vehicle is produced by in wheel motor which is integrated into the wheel rim before the pre-pushed rod contacting with push rod, it can be measured by pedal travel sensor. The in-wheel motor controlled by composite regenerative braking controller outputs the regenerative braking torque in proportional to the pedal travel. If the pedal travel sensor detect that the pre-pushed rod and push rod has contacted with each other, the in-wheel motor controlled by composite regenerative braking controller reduces the regenerative braking torque with increasing the hydraulic brake torque until the regenerative braking torque of in-wheel motor is zero. At emergency braking condition with large pedal travel, the main brake torque is output by hydraulic braking system to insure the braking safety and the regenerative brake torque of in-wheel motor is auxiliary. 


\section{Simulation Model for Electric Vehicle Dynamics with In-wheel Motors}

The simulation model for electric vehicle dynamics with in-wheel motors is constructed by AMESIM. The whole vehicle dynamics model has 15 degrees of freedom inclusive of suspension and steering system model. The hydraulic brake system model and in-wheel motor driving system model is built by AMESIM too, the braking system model and in-wheel motor system model is integrated into vehicle model. The anti-lock braking system is built and integrated into braking system model to prevent wheel sliding.

The vehicle model is shown in Figure 4. The hydraulic brake model is shown in Figure 5. The input variable and output variable is master cylinder pressure and normal compression force on brake pads respectively, the in-wheel motor driving system model is shown in Figure 6. Its input variable is the torque command, battery volts and current and the output variable is the actual torque and speed of the in-wheel motor is output variable.

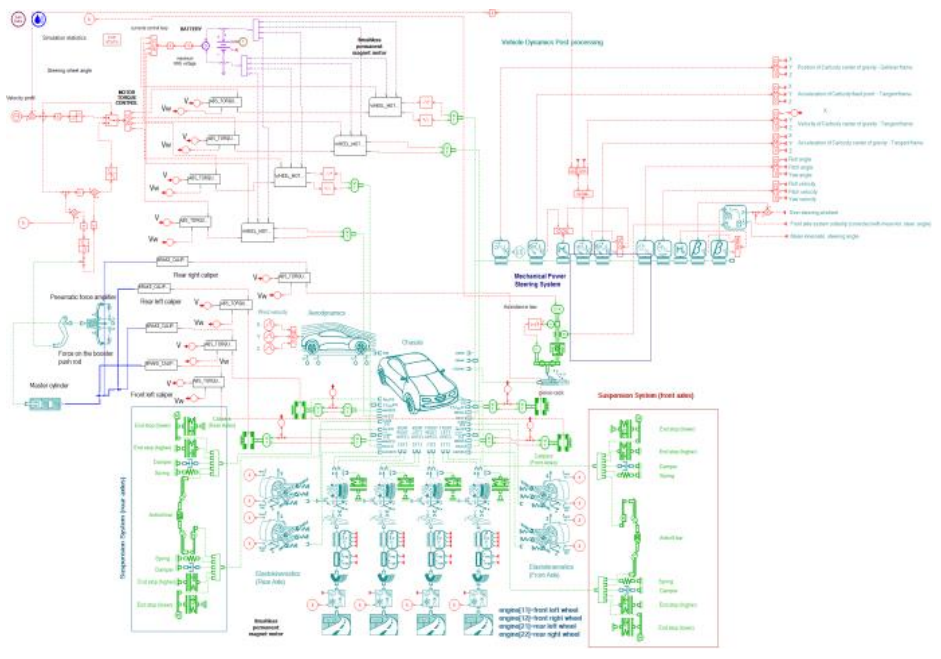

Figure 4. The In-wheel Motor EV Dynamics Model

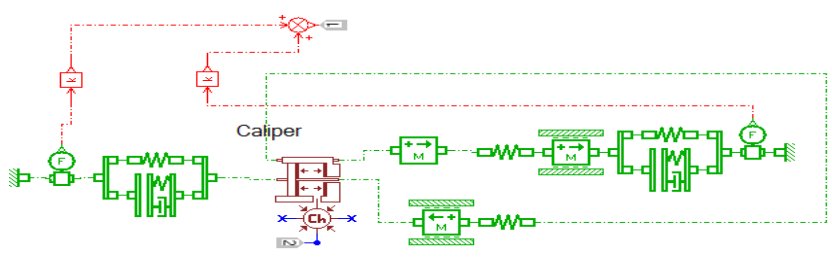

Figure 5. The Hydraulic Brake Model

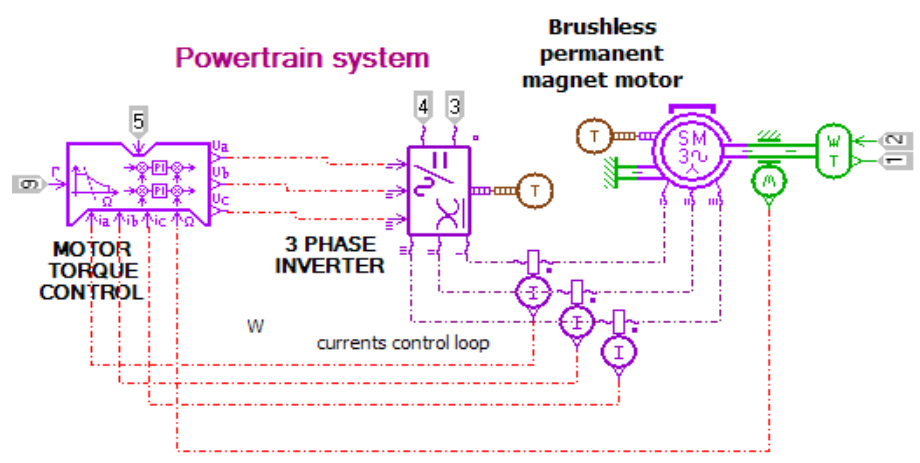

Figure 6. The In-wheel Motor Model 


\section{The Energy Saving Potential of Electric Vehicle with In-wheel Motor}

Generally, the driving cycle is used to evaluate energy consumption of electric vehicle; it is the typical operation condition during vehicle driving. And so the typical driving condition can be used to evaluate the regenerative braking energy too. In this research, the NEDC and FTP75 cycle is used to evaluate the energy saving by regenerative brake with in-wheel motor.

\subsection{NEDC Driving Cycle Simulation}

The vehicle velocity map is shown in Figure 7 in NEDC condition. The simulation is carried out by braking with in-wheel motor only and with hydraulic system respectively to compare energy economy at two braking method.

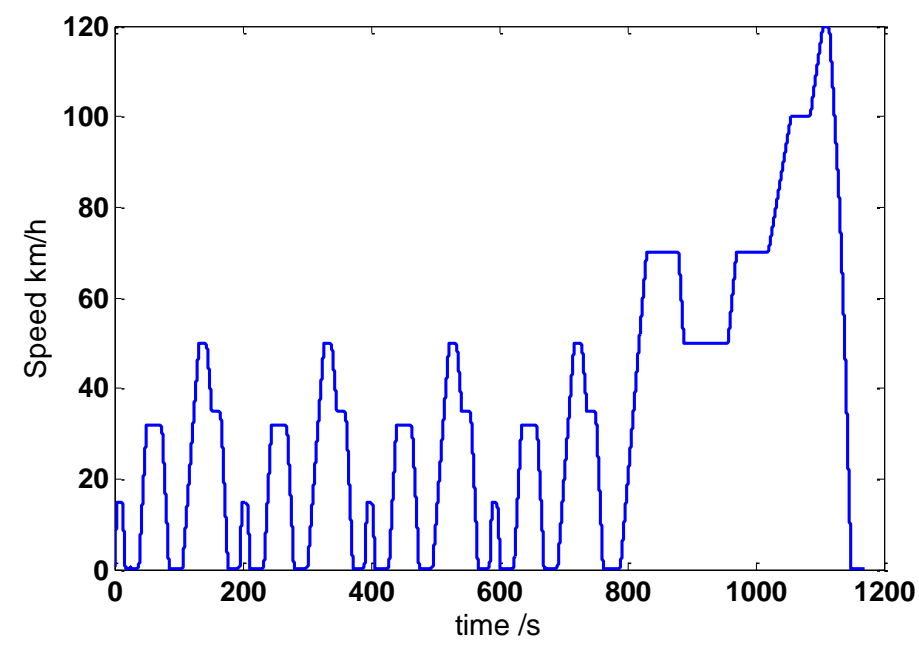

Figure 7. Vehicle Velocity Map in NEDC Cycle

The driving and braking torque of in-wheel motor during driving on NEDC condition with in-wheel motor regenerative braking is shown in Figure 8. The hydraulic braking pressure is zero, namely, there is no hydraulic braking during the simulation condition. And so it is concluded that the in-wheel regenerative braking torque is enough to decelerate the vehicle on NEDC condition with no hydraulic braking. The battery voltage and current during simulation with in-wheel motor braking method is shown in Figure 9. The hydraulic braking torque and in-wheel motor driving torque during simulation with hydraulic braking system is shown in Figure 10. Comparing the regenerative braking for in-wheel motor with hydraulic braking torque in Figure 10 and Figure 8, the two braking torque is equivalent. The contrast of battery SOC for simulations with in-wheel motor regenerative braking and hydraulic braking is shown in Figure 11. It is obvious that vehicle with in-wheel motor regenerative braking method consume less energy than the one with hydraulic braking method during NEDC cycle simulation. The in-wheel motor regenerative braking system can save maximum braking energy to battery. At the end of the NEDC cycle, the SOC for in-wheel motor regenerative braking is higher than the one with hydraulic braking by $0.8 \%$. Compared with the total electricity energy of $2.5 \%$ SOC, the energy saving rate of the vehicle with in-wheel motor regenerative braking achieved $32 \%$. But the one with traditional regenerative braking method is no more than $10 \%$. 


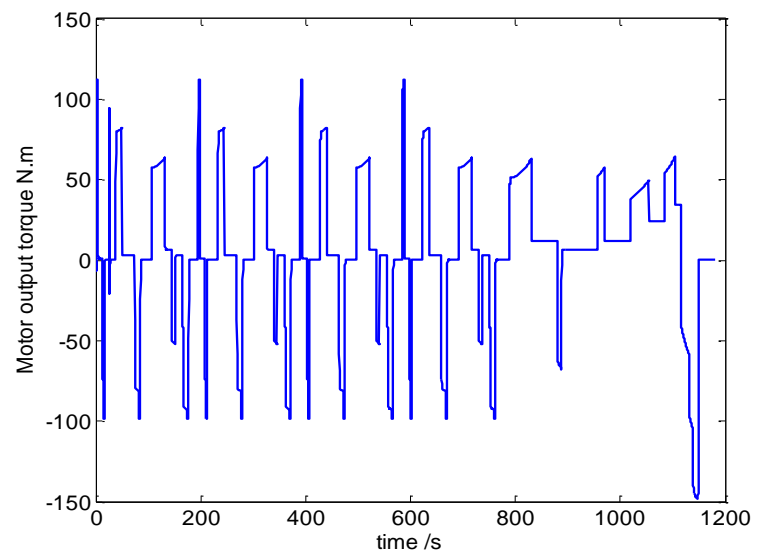

Figure 8. Drive and Braking Torque Output of In-wheel Motor
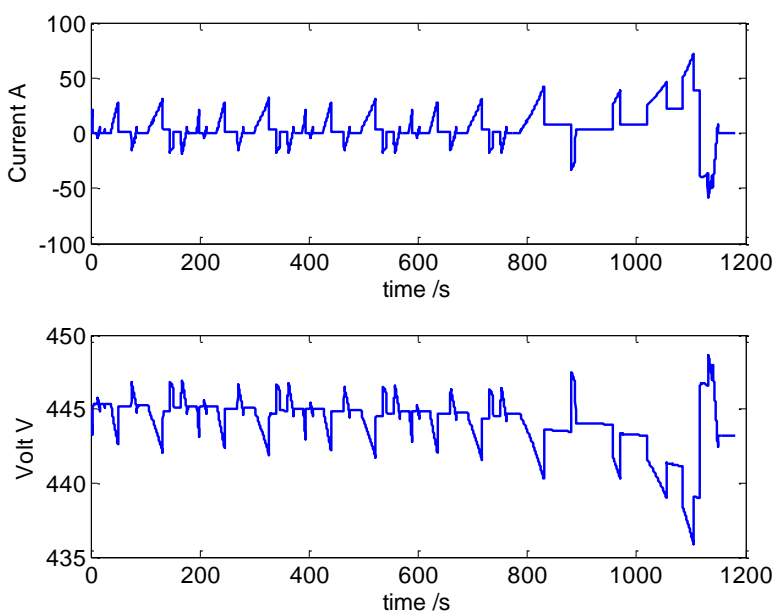

Figure 9. Battery Voltage and Current

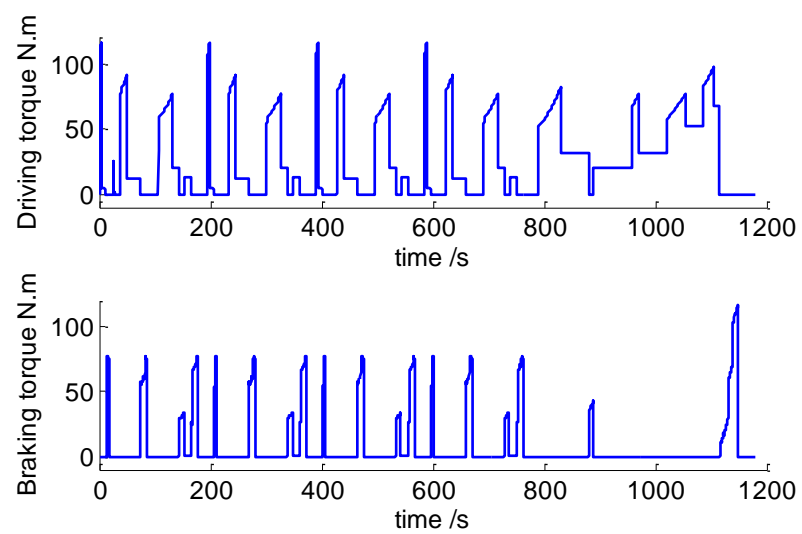

Figure 10. Hydraulic Braking Torque and In-wheel Motor Driving Torque 


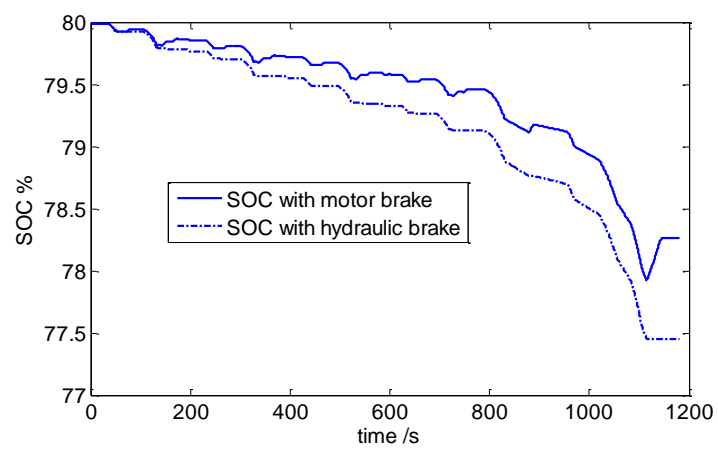

Figure 11. Contrast of Battery SOC for the Two Systems

\subsection{FTP75 Driving Cycle Simulation}

The vehicle velocity map during FTP75 cycle simulation is shown in Figure 12. Compared with the NEDC cycle, it has more braking condition and bigger deceleration. The output torque of in-wheel motor with only in-wheel motor braking is shown in Figure 13. For the bigger deceleration, the braking torque of the in-wheel motor is almost as large as driving torque. It can be seen in Figure 13. The maximum torque during vehicle decelerating is no more than $150 \mathrm{~N} . \mathrm{m}$. the in-wheel motor can output this torque in rated characteristic and the in wheel motor can decelerate the vehicle by in-wheel motor regenerative braking torque continuously [11]. The driving torque of in-wheel motor and the braking torque produced by hydraulic braking system in front axle is shown in Figure 14. Because the braking torque in front axle is bigger than the one in rear axle, the braking torque shown in Figure 14 is bigger than driving torque. The SOC of battery for two braking method is shown in Figure 15. Compared with consumed $2.75 \%$ SOC electricity energy in battery for the vehicle with only in-wheel motor regenerative braking to decelerate the vehicle, the vehicle consumed $4.5 \%$ SOC electricity energy in battery for the vehicle with hydraulic braking system to decelerate the vehicle. For the vehicle total energy consuming, the energy saving rate for vehicle with in-wheel motor regenerative braking achieved 38.9\%. The energy saving effect is more obvious than NEDC for more deceleration in FTP75 cycle. It can extend $39 \%$ of range for driving by electricity energy in FTP75 cycle with no battery adding. On the other hand, the vehicle with in-wheel motor regenerative braking can decrease the $39 \%$ battery requirement on same driving range with the vehicle of hydraulic braking system by electricity energy. It is ideal to decrease the cost and increase the driving range of electric vehicle.

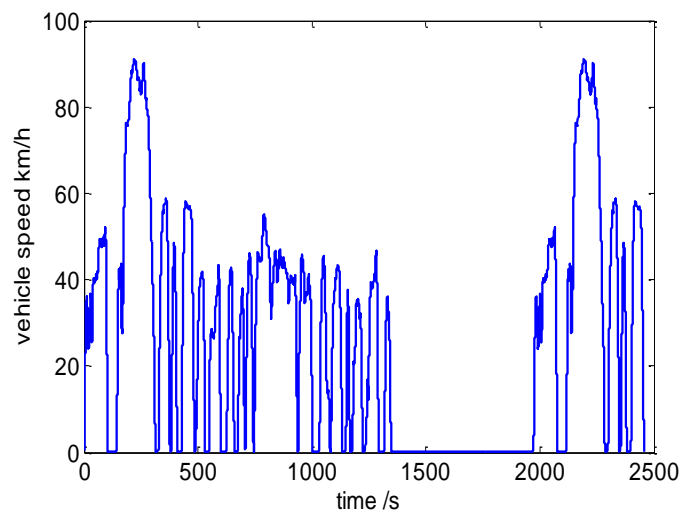

Figure 12. Vehicle Velocity Map in FTP75 Cycle 


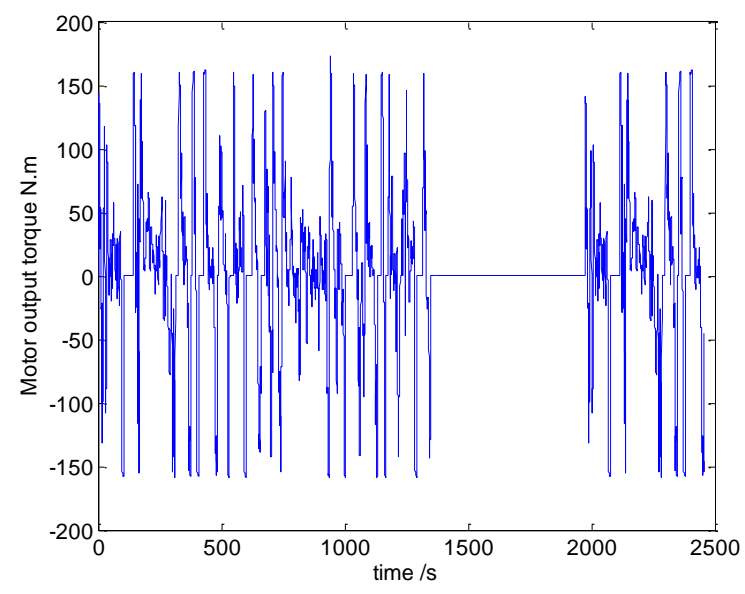

Figure 13. Drive and Braking Torque Output of In-wheel Motor
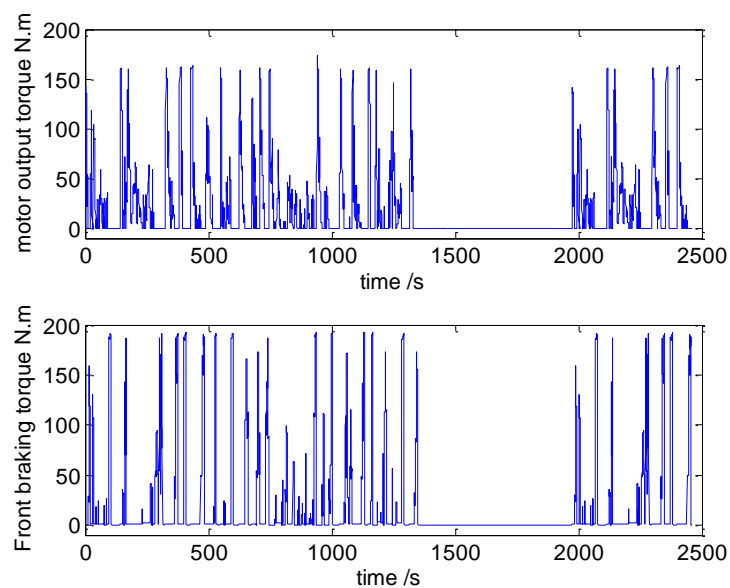

Figure 14. Hydraulic Braking Torque and In-wheel Motor Driving Torque

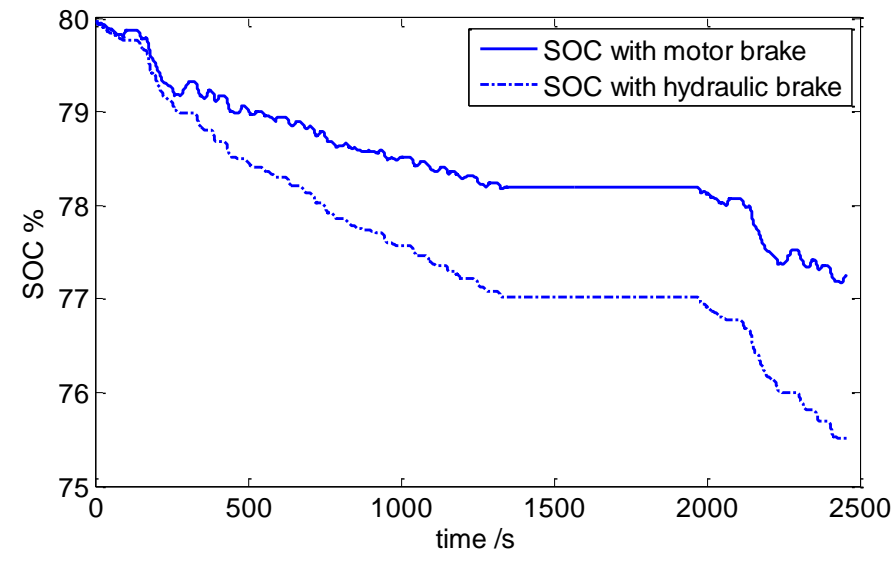

Figure 15. Contrast of Battery SOC for the Two Systems 


\section{Conclusions}

Based on the characteristic of lower speed and higher torque of in-wheel motors for electric vehicle, regenerative braking for electric vehicle driven by in-wheel motors is presented. The novel regenerative braking method can decelerate the vehicle only by in-wheel motor regenerative braking torque on low deceleration value. The vehicle simulation model with hydraulic braking model and in-wheel motor driving system is built. The simulation for vehicle driving on NEDC cycle and FTP75 cycle are then carried out. In a nutshell, the novel regenerative braking method by in-wheel motors can increase regenerative energy during braking condition obviously. The energy efficiency of electric vehicle is increased by more than $30 \%$. It is significant for reducing the cost and extending the driving range of electric vehicles.

\section{References}

[1]. C. C. Chan, "The state of the art of electric and hybrid vehicles", Proceedings of the IEEE, vol. 90, no. 2, (2002), pp. 247-275.

[2]. C. Binggang, Z. Chuanwei, B. Zhifeng, et al., "Technology progress and trends of electric vehicles", Journal-Xian Jiaotong University, vol. 38, no. 1, (2004), pp. 1-5. (in Chinese)

[3]. R. Chicurel, "A compromise solution for energy recovery in vehicle braking", Energy, vol. 24, no. 12, (1999), pp. 1029-1034.

[4]. X. Yan and D. Patterson, "Novel power management for high performance and cost reduction in an electric vehicle", Renewable energy, vol. 22, no. 1, (2001), pp. 177-183.

[5]. H. Sahas, "A modified approach of feeding regenerative energy to the main source", IEEE Trans. Ind. Electron., vol. 43, no. 4, (1996), pp. 510-514.

[6]. Y. Gao, L. Chen and M. Ehsani, "Investigation of the Effectiveness of Regenerative Braking for EV and HEV”, SAE transactions, vol. 108, no. 6, (1999), pp. 3184-3190.

[7]. Y. Gao and M. Ehsani, "Electronic braking system of EV and HEV-integration of regenerative braking, automatic braking force control and ABS", SAE transactions, vol. 110, no. 7, (2001), pp. 576-582.

[8]. M. Panagiotidis, G. Delagrammatikas and D. Assanis, "Development and use of a regenerative braking model for a parallel hybrid electric vehicle", SAE transactions, vol. 109, no. 3, (2000), pp. 1180-1191.

[9]. M. Duoba, T. Bohn and H. Lohse-Busch, "Investigating possible fuel economy bias due to regenerative braking in testing HEVs on 2WD and 4WD chassis dynamometers", SAE transactions, vol. 114, no. 4, (2005), pp. 324-334.

[10].S. R. Cikanek and K. E. Bailey, "Regenerative braking system for a hybrid electric vehicle", American Control Conference, 2002. Proceedings of the 2002. IEEE, vol. 4, (2002), pp. 3129-3134.

[11].C. Mi, H. Lin and Y. Zhang, "Iterative learning control of antilock braking of electric and hybrid vehicles", Vehicular Technology, IEEE Transactions on, vol. 54, no. 2, (2005), pp. 486-494.

[12].J. Paterson and M. Ramsay, "Electric vehicle braking by fuzzy logic control", Industry Applications Society Annual Meeting, 1993, Conference Record of the 1993 IEEE. IEEE, (1993), pp. 2200-2204.

[13].H. Gao, Y. Gao and M. Ehsani, "A neural network based SRM drive control strategy for regenerative braking in EV and HEV", Electric Machines and Drives Conference, 2001, IEMDC 2001, IEEE International IEEE, (2001), pp. 571-575.

\section{Authors}

LiQiang Jin, He received the B.S. From College of Mechanical Engineering, Hebei University of Technology, Tianjin, China in 1999. And Received M.S. And Ph.D. degrees from the College of Automotive Engineering, Jilin University, Changchun, China, in 2002 and 2006, respectively. He is currently a Professor with the College of Automotive Engineering, Jilin University. His research areas include modeling and control of vehicle dynamic systems, Advanced Technology and theory of Electric vehicle with motorized wheels. 
PengFei Chen, He received the B.S. From the College Automotive Engineering, North University of China, Taiyuan, China in 2010. He received the M.S. From the College Automotive Engineering, Jilin University, Changchun, China in 2013. And he is currently working for his D.R. degree in College Automotive Engineering, Jilin University. His interests are vehicle dynamic control, vehicle stability control, EV driven by in-wheel motors.

Yue Liu, He received the B.S. From the College Automotive Engineering, Jilin University, Changchun, China in 2013. And he is currently working for his M.S. degree in College Automotive Engineering, Jilin University. His interests are vehicle dynamic control, vehicle stability control, EV driven by in-wheel motors. 
International Journal of Control and Automation

Vol. 7, No. 12 (2014) 